\title{
HIV-RELATED DISCRIMINATION REPORTED BY PEOPLE LIVING WITH HIV IN LAGOS
}

\author{
AA AKINBAMI ${ }^{1}$, KO WRIGHT $^{2}$, TA ADEYEMO $^{3}$, MO DADA $^{1}$, AO DOSUNMU $^{1}$
}

\begin{abstract}
Objective: Numerous factors have unilaterally and synergistically undermined the success of HIV and AIDS. It is in the light of the foregoing that this study was undertaken to evaluate some discriminatory experiences of people living with HIV and AIDS.

Materials and Methods: This was a descriptive cross-sectional study on people with HIV and AIDS attending an outpatient clinic at Lagos State University Teaching Hospital within a period of 12 weeks. Respondents were recruited consecutively and data was collected with a semi-structured questionnaire. Response rate was $97.7 \%$, analysis was done with Epi-info 6 statistical software.

Results: Approximately one-fifth (17\%) of respondents reported discrimination. Exploration on sources of discrimination showed that people discriminated against mentioned family members as being responsible in $49.1 \%$ of cases, $23.6 \%$ of respondents reported workplace discrimination and only 3.5\% mentioned discrimination experienced by the Government workers.

Conclusion: It is evident that success achieved so far in the fight against HIV and AIDS can easily be eroded if issues of discrimination against people living with HIV and AIDS are not addressed. Various innovative educational strategies targeting all stakeholders may be required if the battle against the spread of the virus must be won.
\end{abstract}

Keyword: Discrimination, PLWHA, HIV, AIDS

\section{Introduction}

Discrimination associated with HIV/AIDS is one of the greatest barriers to preventing further infections and to accessing the care, support and treatment services that allow people living with HIV/AIDS (PLWHA) to lead productive lives. ${ }^{1}$ There is no doubt that discrimination amplifies the complexities of living with HIV. ${ }^{2}$ Moreover, there is some empirical evidence that discrimination may contribute to an increase in HIV-related risk behaviors among both the HIV-positive and HIV-negative. ${ }^{3,4}$

Elford et al examined the extent to which people living with HIV in London reported being discriminated because of their infection. Overall nearly one-third of respondents (29.9\%) reported being discriminated against because of their infection. Of those who reported experiencing HIVrelated discrimination, almost half (49.6\%) said this has involved a health care worker including their dentist $(25.3 \%)$ or primary care physicians $(17.4 \%) .{ }^{5}$ In a similar study in France, Peretti-Watel et al, found $24 \%$ of respondents reported experiences of discrimination in their close social environment (relatives, friends, and colleagues) and 18\% reported unsafe sex during the previous 12 months. ${ }^{6}$

Omoteso studied the perception of university undergraduate to students living with HIV and AIDS in Nigeria. ${ }^{7}$ It was revealed from the study that the attitude of university students was that of discrimination, and rejection towards students living with HIV/AIDS. In a study conducted on 254 journalists in Ibadan, Nigeria, to assess knowledge of acquired immune deficiency syndrome (AIDS), attitude to persons living with HIV/AIDS and reports of AIDS-related issues. ${ }^{8}$ It was concluded that journalists in Ibadan do not have adequate knowledge of AIDS, and many of them show discriminatory attitude to PLWHA, thus undermining their potential

1. Department of Haematology and Blood Transfusion, Lagos State University, College of Medicine.

2. Department of Community Health and Primary Health Care Lagos State University College of Medicine

3. Department of Haematology and Blood Transfusion, Lagos University Teaching Hospital, Idiaraba.

Correspondence: A.A. Akinbami, Department of Haematology and Blood Transfusion, Lagos State University, College of Medicine. E-mail:ajoke_clinic@yahoo.co.uk 
ability and responsibility to educate the public about AIDS.

The possibility of infected members being discriminated against within their own home is not far fetched. It can manifest in the workplace through discriminatory hiring practices, establishment of unfair benefit packages limiting coverage for HIV positive employees. Such policies and behaviors further propagate discrimination in the community by reinforcing negative attitudes towards people living with HIV/AIDS and their families. In some societies, laws, rules, and policies can increase the discrimination of people living with HIV/AIDS. Such legislation may include compulsory screening and testing, as well as limitations on international travel and migration for PLWHA .It is hoped that the more people are informed about HIV/AIDS the less likelihood of discrimination.

\section{Materials and Methods}

This descriptive cross-sectional study was carried out amongst a sample of PLWHA to assess their discriminatory experiences at home and workplace. Participation in the study was voluntary. Patients attending HIV/AIDS clinic of the Lagos State University Teaching Hospital were given selfadministered semi-structured questionnaire. The average daily attendance at the clinic was about 200; the respondents were recruited consecutively on each clinic day.

A total of three hundred and thirty (330) questionnaires were distributed, out of which three hundred and twenty three (323) were answered and returned. The data entry and analysis were done with Epi-info 6.0 statistical software showing frequency tables and various tests of significance is taken at $\mathrm{P}<0.05$.

\section{Results}

A total of three hundred and thirty (330) semistructured questionnaires were distributed, out of which three hundred and twenty three (323) were completed, making a response rate of $97.9 \%$. Research findings revealed that as high as $60 \%$ had not experienced discrimination while $17.6 \%$ experienced discrimination, $13.6 \%$ was indeterminate (Table I). For those who had experienced some discrimination, $49.1 \%$ reported discrimination from family members, $26.3 \%$ at workplace and $3.5 \%$ by the Government as shown in
Table II. Furthermore, out of those discriminated against by family members, $39.3 \%$ claimed to be isolated, whilst $14.3 \%$ of them reported that close contact was avoided. A total of $35.7 \%$ of them were given separate cutlery and plates and $10.7 \%$ were subjected to verbal ridicule. For those who were discriminated against at the workplace, $46.6 \%$ of them were retrenched, $26.6 \%$ redeployed, $20 \%$ isolated, whilst $6.6 \%$ were subjected to verbal ridicule and abuse. Out of the two civil servants who complained of Government discrimination one was isolated, none sacked and one transferred by the Government.

Table I

Experience of discrimination by respondents.

\begin{tabular}{lcc}
\hline $\begin{array}{l}\text { Experienced } \\
\text { Discrimination }\end{array}$ & $\begin{array}{c}\text { Frequency } \\
(\mathrm{Num})\end{array}$ & $\begin{array}{c}\text { Percentage } \\
\%\end{array}$ \\
\hline Yes & 57 & 17.6 \\
No & 196 & 60.7 \\
Don't Know & 44 & 13.6 \\
No Response & 26 & 8 \\
\hline Total & 323 & 100 \\
\hline
\end{tabular}

Table II

Places of discrimination

\begin{tabular}{lcc}
\hline Place & $\begin{array}{c}\text { Frequency } \\
(\mathrm{Num})\end{array}$ & $\begin{array}{c}\text { Percentage } \\
\%\end{array}$ \\
\hline Workplace & 15 & 26.3 \\
Family Members & 28 & 49.1 \\
Government & 2 & 3.5 \\
Non Respondents & 12 & 21.1 \\
\hline Total & 57 & 100 \\
\hline
\end{tabular}

\section{Discussion}

This study revealed $17.6 \%$ of people living with HIV/ AIDS (PLWHA) experienced discrimination in Lagos. This prevalence is lower than the overall prevalence of $29.9 \%$ obtained by Elford et al in London and also lower than $24 \%$ obtained from the France study. ${ }^{5,6}$ Majority of people discriminated against mentioned family members as being responsible in $49.1 \%$ of cases in this study. This is lower than findings from France study in which 24\% reported experiences of discrimination by close social environment (relatives, friends, and colleagues). This may be due to the fact that the majority of the $35 \%$ of respondents who 
disclosed their HIV status publicly in this study, informed members of the family. Workplace discrimination was second in the experiences of PLWHA (26.3\%) of cases were reported. This is followed by discrimination experienced by Government workers (3.5\%).

\section{Conclusion}

A lot still needs to be done to reduce discrimination in the society. The $17 \%$ discrimination prevalence reported in this study is high, and this will undermine the potential ability of all stakeholders to curb the deadly scourge of HIV and AIDS.

The fight against discrimination should become an all-frontal fight, involving the Government, nonGovernmental organizations, non-infected people, and PLWHA and all stakeholders. All hands must be on deck to find a lasting solution to the problem because of the significant percentage of discrimination experienced by PLWHA

\section{References}

1. UNAIDS. AIDS Epidemic Update. Joint United Programmes on HIV/AIDS 2002. Geneva.

2. UNAIDS. Joint United Nations Programmes on HIV/AIDS. Protocol for the identification of discrimination against people living with HIV, 2000, Geneva.

3. Chesney MA, Smith AW. Critical delays in HIV testing and care: the potential role of stigma. Am Behav Scientist 1999; 42(7): 1162-1174.

4. Botnick MR. Fear of contagion, fear of intimacy. J Homosexual 2000;39:77-101.

5. Elford J, Ibrahim F, Bukutu C, et al. Sexual behavior of people living with HIV in London: Implications for HIV transmission. AIDS 2007;21 Supp 1:S 6370.

6. Paretti-Watel P, Spire B, Obada Y, et al. Discrimination against HIV-infected people and the spread of HIV: some evidence from France. PLoS ONE 2007; 2(5): e411.

7. Omoteso BA. Perception of Acquired Immune Deficiency Syndrome as Correlate of Sexual Behaviour among University Undergraduates in South western Nigeria. An unpublished Ph.D. thesis of Obafemi Awolowo University, Ile Ife, Nigeria. 2003.

8. Isibor MD, Ajuwon AJ. Journalists' knowledge of AIDS and attitude to persons living with HIV in Ibadan, Nigeria. African Regional Health Education Centre, Department of Health Promotion and Education, College of Medicine, University of Ibadan, Nigeria. 2004;8(2):101-10 